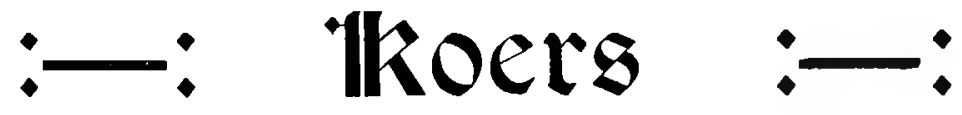

TWEEMAADELIKSE TYDSKRIF

DEEL XIX

\title{
Die Christelike Roeping van die Afrikaner in Afrika.*
}

\section{AFRIKA, DIE „DONKER KONTINENT."}

1. Inleiding.

Ons het in hierdie lesing te doen met 'n magtige onderwerp, en in die tyd tot ons beskikking sal ons dit maar heel liggies kan aanraak. Dit

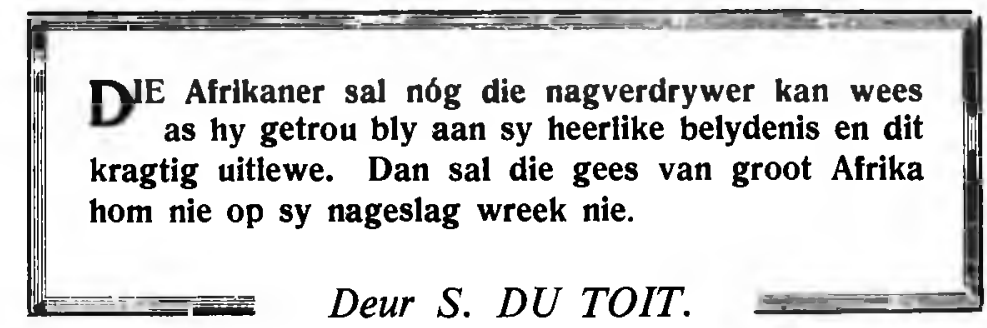

sal ook al genoeg wees as ons onder die indruk kom van die reusagtigheid van die vraagstukke wat hierdie reusagtige kontinent stel. Dr. G. Moerdijk het verklaar: „mensewerk verdwerg in Afrika," en so sal dit ook met hierdie nietige poging wees.

* (Hierdie lesing is opgestel vir 'n lenteskool in Johannesburg. Weens gebrek aan belangstelling is die lenteskool egter nie gehou nie). 
Afrika het eeuelank daar gelê as 'n kontinent vol misteries. Die digter Totius beskryf dit as ,al-stormomring, al-stormbruis, al-onherbergsaamheid." As die ontdekker Bartholomeus Dias in die verbeelding van die digter 'n tweegesprek hou met die gees van die storm, dan is dit die woorde van die gees:

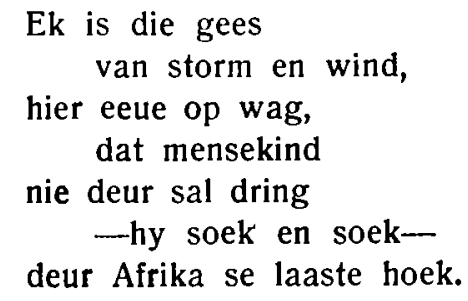

Aan die noordekant die Sahara, aan die suidekant Stormkaap, in die middel oerwoude en moerasse - ondeurdringbaar. Die land van tsetsevlieg, van nagana, van tropiese hitte: al-ondeurdringbaarheid. Luister weer na die digter:

Land waar in skaarse ongewoonheid nog Edens bloei in eewge skoonheid, die boom nog groei in wonderblad, en wonderwater rust'loos spat.

Land waar sahara's golf onendig, die karavaan van dors ellendig, sirokko's hoor wat stoot by stoot verskriklik brul van doem en dood.

Land waar die steppe in tril-verwarming die wêreld gryp in wye omarming; die oog, sy vaste ruspunt kwyt, wegwiegel in oneindigheid.

Land waar die vriendelik-gesinde en swaargelaaide oostewinde met moeite teen die hange uitdra die reën van halwe Afrika.

Land waar die uitgedorde Weste ontvang die armelike reste:

die Oosland word 'n wilde tuin, die Wesland dorheid en ... 'n duin. 
Land waar die son skroei in sy klaarte, die spooksel rondwaar van die maerte, waar hoop die hart nie meer kan beur, en wanhoop die verwagting skeur.

Land waar ek hoor gegons van vlerke

by kleingediert se onheilswerke: sprinkaan, insekte- en vlieëmag, die leêrs van die kiemenag.

Land ... kusrotse is die strenge wagte waaragter woel die onheilsmagte.

Die maar meld uit jou ou-ou tyd net skrik en onherbergsaamheid.

(Uit Donker Afrika, bl. 38 e.v.).

\section{Gesteldheid van die land.}

In baie opsigte is Afrika 'n unieke kontinent. In grootte is daar slegs een vasteland wat die van ons oortref, nl. Asië. Ingeslote die eilande wat Afrika omring, beslaan dit ongeveer 11,500,000 vierkante myl teenoor 16,000,000 van Asië. Dit is driemaal so groot as Europa en anderhalf maal so groot as Noord- of Suid-Amerika. Die V.S.A., China, Indië en Europa kan almal gesamentlik op Afrika geplaas word.

Dit is die enigste kontinent waarvan die bewoners feitlik sonder uitsondering swartes is. Dit is die enigste vasteland waarvan die inheemse godsdienste sonder heilige geskrifte en sonder bepaalde omvattende sisteme is. Ons kontinent is die mees tropiese en strek ongeveer 35 grade uit aan weerskante van die ekwator.

Dit word omsoom deur laagliggende kusland, met 'n breedte vanaf $1 \mathrm{myl}$ tot 200 of $300 \mathrm{myl}$. Vanaf hierdie kusland styg die grond om plato's rondom die hele kontinent te vorm, totdat die uitgestrekte hooglande van die binneland bereik word. Dit is asof geweldige, omsirkelende trappe opvoer na 'n reusagtige sentrale verhoog van ongelyke oppervlakte, met berge, mere en riviere. Rondom die hele Afrika loop bergreekse, min of meer parallel met die kus, asof hulle die binnelande wil afsluit met 'n borswering:

Die binneland bestaan hoofsaaklik uit twee tafeliande. Die eerste, die noord-westelike, gemiddeld ongeveer 1300 voet hoog, is die grootste en strek vanaf die berge van Abessinië na die Atlantiese kus. Dit daal geleidelik noordwaarts in die rigting van die Sahara en styg na die suide om aan te sluit by die suid-oostelike plato op 'n hoogte van ongeveer 3000 voet. Die suid-oostelike plato strek vanaf die Abessiniese 
berge tot aan die groot Karoo in Kaapland. Die grootste hoogte word bereik in die ooste, waar, selfs onder die ekwator, vulkaniese berge oprys wat aansienlik hoër as Mont Blanc is en beklee met ewige sneeu. Hier gee die tweede grootste meer in die wêreld, die Victoria Nyanza, geboorte aan die tweede langste rivier, die Nyl. Al die riviere moet deur die bergrand van die plato breek om die see te bereik. . As gevolg van die snelle daling is die meeste riviere dus onbevaarbaar. Die kuslyn is baie ongebroke en het daarom weinig hawens.

Die reënval is uiters ongereeld en verskillend in die afsonderlike geweste. Dit wissel van 70 tot 350 duim per jaar in die Kameroen, Nigerië, Sierra Leone, die Guineakus en die Kongobekken, tot niks in die uitlopers van die Sahara en die suidwaartse woestyne, langs byna die hele Weskus. . Op die hoogland wat uit die oostelike gedeelte van die Unie tot aan die "White Highlands" van Kenia strek, wissel dit meestal tussen 20 en 40, selde meer, en is byna sonder uitsondering ongereeld. Die gedeeltes op die hoogland van Afrika waar staatgemaak kan word op gereelde reënval, is nie om van te praat nie.

Aan wêreldstandaarde gemeet, is die grond van Afrika arm. Hierdie feit saam met ons ongeëwenaarde „rykdom" aan plae en peste maak die verbouing van grond dikwels 'n ontmoedigende onderneming. Die veelgeroemde rykdom aan minerale is ook nie verbysterend nie. Eindelik is net die Unie ryk daaraan, en dan die koperstreek van N. Rhodesië, asook die Katangagebied in die Belgiese Kongo. Sewentig persent van Afrika se steenkoolvoorrade is afkomstig uit die Unie. Metale kom wel voor in ander dele maar nie in sulke hoeveelhede dat dit lonend bewerk kan word nie. (Gegewens ontleen aan artikels deur mnr. W. van Heerden van die redaksie van Dagbreek).

\section{Die bevolking.}

Die digtheid van die bevolking wissel met die digtheid van die reënval. Die verskillende rasse is egter volgens 'n ander plan gedifferensieer. In die noorde word Semiete en Hamiete gevind. Ten suide van hulle gebied is daar die groot swart gordel wat strek vanaf die Atlantiese Oseaan tot aan die Nyl--'n mengeling van Negerstamme met 'n onontwarbare patroon van honderde tale. In die suide is al die stamme, met uitsondering van die klein groepies Boesmans en Hottentotte, van Bantoeoorsprong.

Die Semitiese bevolkingsgroepe is veral van Arabiese herkoms, terwyl die Hamiete ontstaan het uit 'n vermenging van Semiete en een of ander donkerder ras. Die Bantoe is die jongste en die taaiste ras van Afrika. 
Hierdie rasse leef hoofsaaklik nog in ' $n$ toestand van primitiewe barbaredom, in onkunde en bygeloof. Dit is waarlik of op hulle ' $n$ vloek rus. Dit is of Afrika die verswelger van beskawinge is. Die ,gees van donker Afrika" sê dan ook:

Ek is die gees van dood en doem en vloek wat, saam met ander, nasies moes verlei. Tot straf moet ek in hierdie woestheid bly waar ek vergeefs vir my 'n woonplek soek.

Ek weet van Gam en van sy snode daad, hoe hom die vloek van Noag, stap vir stap, verskrik het én al sy nakomelingskap-

'n vaderlike vloek brand vroeg en laat.

Met hierdie vloek versterk het ek gegaan na Afrika, die onbekende land, en dit verskrik met eewge moord en brand, met ramp en plaag tot waar die Stormkaap staan.

Dit is asof beskawinge tevergeefs hier kom:

Waar is die manne wat ons wou beveg?

Egiptenaar, Sidoniër en Moor?

Ruïnes dek hul te vermeetle spoor,

Atlantis en Simbabwe-hul is wég.

Ek is dit wat die sterkste hoop verbreek.

Ek maak die taaiste werklus tot 'n spot,

die Trekkersideaal ... 'n swerwerslot.

Ek sal my op jou nageslag nog wreek.

- Gedurende die eeue het die naturelle hier 'n lewe gevoer wat vir die kultuurvooruitgang van die wêreld weinig of niks beteken het nie. Beskawinge het wel ondergegaan soos in 'n groot moeras, maar Afrika suid van die $\mathrm{Nyl}$ het aan die wêreld eintlik niks blywends gebring nie, behalwe insoverre dic primitiewe kultuuruitinge tog toon dat ons met mense te doen het en nie met diere nie.

$\mathrm{Na}$ waarheid is die inboorlingrasse in Afrika "die bedorwe kinders van die natuur" genoem. Vgl Naylor in Daybreak in the dark continent: "Throughout much of his continent nature is lavishly kind to him. She feeds him almost without the asking. She clothes him with tropical sun- 
shine. If his necessity or his vanity calls for more covering, she furnishes it-again with no excess of labour on his part-from leaf or bark or skin. Everything that has to do with the primitive demands of his physical well-being is, as it were, ready at his hand. Intellectually, he is untrammelled by tradition or practice. He has kept himself free from educational entanglements. No abc's, no puzzling multiplication tables, no grammatical rules, no toiling over copybooks, harass his brain."

\section{Godsdiens.}

In ooreenstemming met die algemene mentaliteit vind ons by die inboorlingrasse die mees primitiewe vorme van godsdiens. Die naturel glo aan ' $n$ menigvuldigheid van geeste, meestal van demoniese aard. Hierdie geeste laat hom nooit met rus nie. Merkwaardigerwys is hy egter tog die onbekommerde, blymoedige natuurkind. Danksy sy temperament wat van nature "easy-going" is, voel hy hom tog op sy gemak te midde van die ,heirleger" van geeste. On die goedgesindheid van die geeste te verkry moet allerlei towermiddels gedra word. Vanselfsprekend is die toordokter van groot betekenis.

Die grens tussen geeste en gode is nie skerp belyn nie. Tog is daar ook gode: individuele gode, familiegode, stamgode ens. Ook die gode vertoon demoniese trekke. Die meeste van hulle is eintlik barbare in die groot: hulle swelg in dronkenskap en onsedelikheid.

By die mees primitiewe stamme word ook die geloof in 'n Hoogste Wese gevind. Dit skyn of die waarheid hier in 'n dowwe skemering deurbreek.

Aan die lewe van die mens word nie veel waarde geheg nie. Verskillende bygelowe, gepaard met waarseggery, towery, mense-offers, kannibalisme verg elkeen hul tol aan lewens. Afgesien daarvan sterf menigtes van kinders as gevolg van onhigiëniese toestande.

Die volgende samevatting van Naylor teken die hele lugubere situasie: "Delicacy permits but the most guarded references to the revolting brutality and nauseating licentiousness which are the legitimate offspring of pagan gods and their religion. To be consistent with his perverted conceptions of religion, the African cannot be other than he is. Brutality lies not in himself, but in his religion."

\section{DIE KERSTENING VAN AFRIKA.}

\section{Die ontdekking van ons kontinent.}

Voor die Christelike tydperk was daar slegs van die gebiede langs die kuste van die Middellandse en Rooi See noukeurige kennis, asook van die Nylgebied, die groot woestyn en Etiopië. 'n Enkele keer het 'n ekspedisie dieper ingedring, en dit is moontlik dat die Fenisiërs die 
kuste bevaar het, maar werklike kennis van die binnelande het beperk gebly.

Vanaf die vyftiende eeu A.D. begin 'n tydperk van ontdekkinge. Portugal, in die persoon van prins Hendrik die Seevaarder (1394-1460), neem die leiding in die eksplorasie van die Weskus. Hendrik gaan selfs so ver as die Guinea-kus. In 1486 gaan Dias om die Kaap, en Vasco da Gama maak die nuwe roete na Indië 'n voldonge feit. As die Engelse, Franse en Hollanders sien watter handel die Portugese met Afrika dryf, begin ook hulle, reeds voor die einde van die sestiende eeu, 'n lewendige handel met die stamme van die Weskus.

Gedurende die sewentiende eeu ontstaan min of meer permanente nedersettinge. Die kaarte van die tyd toon egter dat daar nog volslae onkunde heers met betrekking tot die werklike toestande in die binnelande. Die negentiende eeu sou eers die eeu van groot ontdekkinge word, danksy veral die bemoeiinge van die Engelse "African Association," later voortgesit deur die "Royal Geographical Society of London." In hierdie verband dink ons aan die beroemde manne Stanley en Livingstone.

\section{Die lig van die Evangelie in Afrika.}

Die profesieë van die O.T. het reeds voorspel dat ook Afrika in die seëninge van die Evangelie sal deel. Ons kan maar net verwys na Psalm 68: 32, Ps. 87: 4, Jes. 19: 19. Dit hoef ons nie te verwonder nie dat 'n hofdienaar van Etiopië een van die eerstes is wat hulle tot die Christendom bekeer.

In die tweede en derde eeue van ons jaartelling het die Christendom hom oor die hele Egipte en Nubië uitgebrei, sodat Noord-Afrika prakties 'n Christelike land geword het. Belangrike teologiese skole het hier gebloei, met name die sgn. Alexandrynse en Noord-Afrikaanse. Ons dink aan groot kerkvaders wat op ons vasteland gewerk het, soos Origenes, Clemens Alexandrinus, Augustinus, Cyprianus, Tertullianus. Groot sinodes is op Afrikaanse gebied gehou, soos die van Hippo en Karthago, waar finaal besluit is oor die kánon van die Heilige Skrif.

Die Mohanmedanisme het egter in die sewende eeu as 'n gesel van God gekom en hom stormenderhand oor die Sahara na Wes-Soedan en langs die Ooskus tot by Zanzibar uitgebrei. Net in Abessinië het iets van die Christendom oorgebly en dit nog wel in verbasterde vorm. Tot vandag toe bly die Islam een van die grootste hinderpale by die kerstening van Afrika.

$\mathrm{Na}$ hierdie ramp sou die duisternis van die heidendom weer swaar oor Afrika hang. Gelukkig dat ontdekking en sending van die begin af 
saamgehang het. Prins Hendrik die Seevaarder kan beskou word as die pionier onder baie sendelinge wat ook ontdekkers was. By Livingstone was die bekering van die heidene 'n brandende passie. Jesuïtiese sendelinge ontdek vroeg in die sewentiende een die Blou Nyl, terwyl Krapf en Rebmann se togte lei tot die ontdekking van die groot mere. In die twintigste eeu word belangrike sendingswerk gedoen in verskillende gebiede, soos die Soedan, Nigerië, Abessinië, Nyassaland, o.m. ook deur die N.G. Kerke in S.A.

Wat die kerstening van Suid-Afrika betref, is dit allereers merkwaardig dat die lig van die Evangelie nie oorland vanaf die noorde gekom het nie, maar dat klein skepies dit oor die groot waters moes bring na die uiterste suidpunt, vanwaar dit weer noordwaarts sou beweeg. Die Hollanders het dadelik met sendingswerk begin, en die arbeid sou voortgeset word deur Engelse. 'n Mens dink met piëteit aan 'n man soos Moffat, wat reeds voor die Groot Trek in Namakwaland en Bechuanaland met taaie volharding gewerk het. Ongelukkig het sommige sendelinge die ideë van die Franse Revolusie ten opsigte van die natuurmens en die gelykheid van alle mense onderskrywe (ons dink veral aan Philip en Van der Kemp), met funeste gevolge vir die uitbreiding van Gods Koninkryk in ons vaderland. In Gods Raad sou egter juis hierdie beleid een van die drangredes wees vir die Groot Trek waardeur die Afrikaner die ontginner en die nagverdrywer van die binnelande van Afrika sou word.

Tans word deur Afrikaanse, Duitse, Switserse, Engelse e.a. kerke intensief sendingswerk gedoen. Die naturelle het, helaas, egter ook die prooi geword van die versplintering van die Protestantse Christendom, sodat onder hulle honderde sektes aangetref word.

Hierby mag nie vergeet word wat die owerheid en maatskaplike instellinge doen tot opheffing van die naturel nie. Ons hoef maar net te herinner aan die onderwys, aan gesondheidsdienste en aan ontwikkeling van die reserwes.

\section{Huidige situasie en probleme.}

Veral sedert die tweede wêreldoorlog het daar 'n geweldige kentering gekom in die houding van die grootmoondhede ten opsigte van Afrika. Die besef dat in 'n eventuele wêreldbotsing Europa miskien spoedig heeltemal agter die ystergordyn kan verdwyn, het die blik op Afrika gerig. Eensdeels word besef dat Afrika 'n uiters belangrike rol in die strategie kan speel, en anderdeels word op Afrika gebou ten opsigte van die voedselproduksie vir die wêreld. Daarby kom dat ons vasteland moontlik 'n groot getal kan herberg van hulle wat Europa verlaat. 
Amerika, Frankryk, Engeland en België speel in hierdie opsig 'n belangrike rol. Planne word beraam vir die bou van paaie, spoorweë ens., terwyl ook die lugverbindinge aandag geniet. Miljoene ponde sal in sekere onderneminge belê word. België beplan om $£ 400,000,000$ gedurende die volgende tien jaar in die Kongo te bestee. Engeland is besig om $£ 120$ miljoen pond in sy kolonies te belê, ' $n$ groot deel daarvan in Afrika. Frankryk is besig met 'n tienjaar-plan in Ekwatoriale Afrika. Die Portugese beoog 'n belegging van by die $\$ 16$ miljoen in Angola en waarskynlik 'n groter bedrag in Mosambiek. Suid-Rhodesië trek miljoene aan kapitaal-uit Engeland, Amerika en die Unie. Oeganda bou'n kragstasie vir $\$ 13$ miljoen, en om die kroon op alles te plaas het die Unie in die afgelope jaar om en by $\$ 80$ miljoen pond aan private fondse uit die buiteland getrek. Oral is ontwikkeling aan die gang. (Gegewens ontleen aan 'n artikel van W. van Heerden).

Tegelykertyd word egter ook die probleme meer, veral as gevolg van die Britse imperiale beleid ten opsigte van die inboorlinge. Hierdie beleid sal vir die blanke op die lang duur 'n vuurproef word. Die eksperiment wat Engeland met die bevolking van die Goudkus begin het, deur naamlik aan woeste barbare selfregering toe te ken, sal wydverspreide reperkussies hê. Oral kom daar by die naturelle 'n begeerte tot behartiging van hul eie belange, en hul uitinge teenoor die witman is nie byster simpatiek nie.

Ongelukkig is daar as gevolg van 'n beginselverskil geen samewerking tussen die Unie en sy noordelike buurstate nie, inteendeel dit skyn of daar steeds groter verwydering kom. Die skema vir federasie tussen die twee Rhodesiës en Nyassaland is ongetwyfeld ten dele bedoel om S. Rhodesië van die Unie te vervreeemd.

Dit alles maak die bestaan van die witman maar problematies. In Tanganyika het die wetgewende vergadering wel ongeveer 16 verkose lede, maar hulle sal verkies word volgens 'n stelsel wat kan meebring dat geen enkele blanke die paal haal nie. Blankes in Tanganyika besef dat hulle toestand by die dag meer onuithoubaar word. En die witman van Kenia vrees dat op hom dieselfde lot wag. Hulle het reeds 'n tyd gelede na S. Rhodesië 'n deputasie gestuur om hulp te vra. NoordRhodesië word prakties as 'n swartmansland beskou, en die blankes is die "non-Africans."

Baie belangrik is die opmerkings van Sangiro. Hy vermeld dat onder die naturelle in Tanganyika ' $n$ heeltemal ander gees is as toe hy vyftien jaar gelede daar was. Die naturel in dié gebied het totaal geen respek vir die blanke nie. Hy groet hom nie en sal hom onderstebo loop as dit daarop aankom. Volgens Sangiro het al die moeilikhede hul oorsprong 
in die daad van die Britse Empire wat die gebied onder die voogdyskap van die V.V.O. geplaas het.

Tot oormaat van ramp kom hier nog die Kommunistiese gevaar by Stalin sal ook wel sy oog op Afrika gerig hê. Uit verskillende gebiede word berig dat die Kommunisme op subtiele wyse invloed probeer verkry. En dit het by die onontwikkeldes 'n vrugbare teelaarde omdat aan hulle 'n Utopia beloof word. (Gegewens ontleen aan artikels van dr. J. D. du Toit en dr. D. W. Kruger in Die Kerkblad).

\section{DIE TAAK EN ROEPING VAN DIE AFRIKANER.}

\section{Die lewens- en wêreldbeskouing van die Afrikaner.}

Tydens die derde eeufees van ons volksplanting sal ons ook kan gedenk uit watter rots die Afrikaner gekap is. Die Afrikaner stam van Calvinistiese Nederlandse en Franse voorouers-en hierin lê 'n hele wêreld van gedagtes opgesluit.

In die Calvinisme vind ons die mees harmoniese en die mees konsekwente Christendom, 'n lewens- en wêreldbeskouing wat sy mag in die geskiedenis, ook van ons volk, reeds bewys het.

Die Calvinis bely die absolute soewereiniteit van die Almagtige God, wat oor alle dinge regeer. Hy glo dat Christus Koning is en dat aan Hom alle mag in die hemel en op die aarde gegee is. Omdat hy God vrees en krygskneg van Christus is, vrees hy niks en niemand anders nie; Hy is oortuig van 'n goddelike roeping en diens. Oral waarheen hy trek, wil hy die eer van sy God en Koning soek. Hy is daarvan oortuig dat die lig van die Evangelie ook moet val op die gebiede van staat en maatskappy. Hy glo da aan alle mense reg moet geskied, van watter ras of kleur hulle ook mag wees.

Maar hy weet ook dat daar allerlei verskille van ras, kleur, intelligensie ens. is, en daarom kan hy nie die gelykstellingsbeleid van die liberalis onderskrywe nie. Hy wil teenoor die beginsel van die Revolusie die beginsel van die Evangelie stel. Daarom aanvaar hy die beginsel van voogdyskap van die kant van die meer bevoorregte teenoor die minder bevoorregte.

Die Boer met sy wa was die nagverdrywer van Afrika. Hier aan die suidpunt van Afrika hou 'n blanke, Christelike beskawing nou al drie eeue stand. En die Boer is nog steeds besig om noordwaarts te beweeg, tot groot ergernis van diegene wat hom nie goedgesind is nie. $\mathrm{Hy}$ is oortuig dat sy beleid van apartheid en voogdyskap sowel vir hom as vir die naturel die beste is, omdat dit an albei volkome geleentheid gee vir ontwikkeling, en omdat hy weet wat die vrugte van die verbastering van 
heterogene rasse is. Die Afrikaner is hier gebore en getoë, en hy is met hierdie bodem saamgegroei.

\section{Die toekoms.}

Die huidige regering het reeds veel gedoen om ons roeping in Afrika uit te lewe. Ons dink aan die spesiale sending van adv. Te Water na verskillende regerings, aan die groot pan-Afrikaanse vervoerkonferensie wat 'n tyd gelede gehou is, aan die samesprekinge oor verdediging wat in Nairobi plaasgevind het, aan die arbeid wat deur Kerk en Staat in die Unie gedoen word aan die naturel. Ons neem op die oomblik waarlik die leiding in Afrika.

Reeds in die vorige eeu het ds. S. J. du Toit 'n brosjure geskryf met die titel: "Afrika het land der toekomst." Dit skyn of die volke van die wêreld hierdie stelling tans onderskrywe. Ons moet ons egter nie illusies maak nie. Die probleme is ontsaglik in grootte en getal. Ons het daar genoeg aanduidinge van gegee Tog moet ons moedig die toekoms ingaan. Tereg sê W. van Heerden dat wat Afrika kortkom aan intensiteit, vergoed word deur sy ontsaglikheid. Afrika kan-volgens hierdie gesaghebbende-in die ongunstigste omstandighede sy produksie baie male vergroot, en die meeste van sy probleme kan oorkom word deur die wetenskap, deur kapitaal en deur arbeid. Van hierdie drie beskou Van Heerden die arbeid as die vernaamste. Hy is daarvan oortuig dat Afrika nie kan ontwikkel nie as die miljoene naturelle nie geleer kan word om hul ingebore luiheid prys te gee en produktief te werk nie.

Ons wil hier iets byvoeg: Naylor verklaar tereg: „To be consistent with his perverted conceptions of religion the African cannot be other than he is. Brutality lies not in himself, but in his religion. Even when slightly separated from his religion, and for a short time influenced by Christianity, he has proved to be a model of docility, trustworthiness, and inherent kindness. The pagan African is what he is because of his religion. Change his religion and you change the African." Hierdie woorde beklemtoon die absolute noodsaaklikheid van die evangelisering van die inboorlinge. Al die arbeid wat aan hulle ten koste gelê word, is tevergeefs solank as hulle in die heidense bygeloof verstrik bly.

Dit hou tegelykertyd in dat die Afrikaner self sy Christelike erfenis moet waardeer. Wat 'n treurige skouspel is dit wanneer die blanke wel roem op sy blanke vel maar origens op heidense wyse leef. En daar is onrusbarende tekens onder ons volk. Ons hoef dit nie vir $u$ op te noem nie. Die Afrikaner sal nóg die nagverdrywer kan wees as hy getrou bly aan sy heerlike belydenis en dit kragtig uitlewe. Dan sal die gees van groot Afrika hom nie op sy nageslag wreek nie. 